University of New Hampshire

University of New Hampshire Scholars' Repository

\title{
$8-2008$
}

\section{Caretaker Satisfaction With Law Enforcement Response to Missing Children.}

\author{
Heather Hammer \\ Temple University \\ David Finkelhor \\ University of New Hampshire - Main Campus, David.Finkelhor@unh.edu \\ Richard Ormrod \\ University of Northern Colorado \\ Andrea J. Sedlack \\ Westat, Inc. \\ Carol Bruce \\ Westat, Inc.
}

Follow this and additional works at: https://scholars.unh.edu/ccrc

Part of the Criminology Commons

\section{Recommended Citation}

Heather Hammer, David Finkelhor, Richard K. Ormrod, Andrea J. Sedlak, \& Carol Bruce. Caretaker satisfaction with law enforcement response to missing children. Juvenile Justice Bulletin - NCJ217909 (pgs. 1-8). Washington, DC: US Government Printing Office.

This Article is brought to you for free and open access by the Research Institutes, Centers and Programs at University of New Hampshire Scholars' Repository. It has been accepted for inclusion in Crimes Against Children Research Center by an authorized administrator of University of New Hampshire Scholars' Repository. For more information, please contact Scholarly.Communication@unh.edu. 

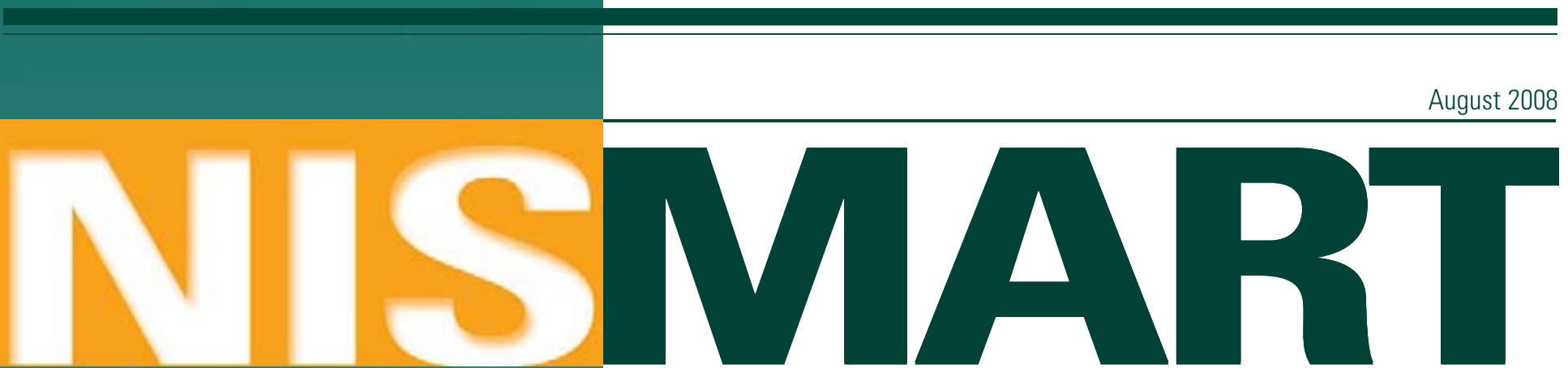

National Incidence Studies of Mi ssing, Abducted, Runaway, and Thrownaway Children

Office of Justice Programs

Innovation • Partnerships $\bullet$ Safer Neighborhoods www.ojp.usdoj.gov

\section{Caretaker Satisfaction With Law Enforcement Response to Missing Children}

\author{
by Heather Hammer, David Finkelhor, \\ Richard K. Ormrod, Andrea J. Sedlak, \\ and Carol Bruce
}

This series of Bulletins summarizes findings from the Second National Incidence Studies of Missing, Abducted, Runaway, and Thrownaway Children (NISMART-2). The main purpose of the series is to provide a clear picture of how many children become missingand why. Bulletins in the series offer national estimates of missing children based on surveys of households, juvenile residential facilities, and law enforcement agencies. The Bulletins also present statistical profiles of these children, including their demographic characteristics and the circumstances of their disappearance. In addition, the series offers analyses of selected special topics, based on NISMART-2 data.

This Bulletin examines satisfaction with law enforcement from the perspective of all primary caretakers who contacted police when one or more of their children experienced a qualifying episode in the Second National Incidence Studies of Missing, Abducted, Runaway, and Thrownaway Children (NISMART-2) National Household Survey of Adult Caretakers. Qualifying episodes include children with police contact who were abducted, 
ran away, or were thrown away and children who were missing involuntarily or for benign reasons. The National Household Survey of Adult Caretakers was conducted during 1999 and reflects a 12-month period.

\section{Key Findings}

- Despite current case-management guidelines for missing and abducted children that recommend the dispatch of officers in response to all missing child cases reported to law enforcement, police were dispatched to the household or scene for only an estimated 68 percent of reported missing child type episodes.

Among the missing child type cases considered in this Bulletin, researchers found no statistically significant differences to indicate that officers are more likely to be dispatched in any particular type of episode.

Caretakers were satisfied with the way in which police handled the case in an estimated 74 percent of the episodes that involved the dispatch of officers to the household or scene, compared with 35 percent of the episodes in which officers were not dispatched.

Police arrived at the household or scene in less than 30 minutes after they were contacted in an estimated 70 percent of episodes involving the dispatch of officers.

Caretaker satisfaction with how the police handled the case is associated with the time it took police to respond. Whereas caretakers were satisfied with the police response in 84 percent of the episodes in which the police arrived in less than 30 minutes, they were satisfied in only a little more than half (54 percent) of the episodes in which the police took 30 minutes or longer to arrive at the household or scene.

- Caretaker satisfaction with how the police handled the case is associated with the type of episode. Caretakers are least satisfied with the way in which police handled family abductions (45 percent).

\section{Conceptualizing the Problem}

Because the initial response of law enforcement agencies is "unquestionably one of the most critical in the entire missing-child investigative process ... it is recommended that law-enforcement agencies respond to every report of a missing child as if the child is in immediate danger" (Steidel, 2006:33). It is further recommended that investigators consult, as a resource, the guidelines contained in the "Investigative Checklist for First Responders" included in Missing and Abducted Children: A LawEnforcement Guide to Case Investigation and Program Management (Steidel, 2006).

With these recommendations in mind, the research team designed NISMART-2 to capture detailed information about the time police took to respond when contacted, whether officers were dispatched to the household or scene, the investigative steps officers followed when they arrived, and the level of caretaker satisfaction with law enforcement's handling of the case. This Bulletin examines the role of law enforcement in all of the NISMART-2 missing child type episodes with any police contact that primary caretakers disclosed in the National Household Survey of Adult Caretakers, including episodes in which the child was reported missing, recovered from a known location, or brought to the attention of law enforcement for some other reason.

\section{Methodology}

Two characteristics differentiate the findings reported in this Bulletin from others reported in the NISMART-2 series and do not allow for comparisons with estimates in previously published Bulletins. First, in contrast with the other Bulletins in this series that are more concerned with overviews and specific episodes and that unify data across the NISMART-2 surveys, this Bulletin relies exclusively on the National Household Survey of Adult Caretakers because this is the only NISMART-2 component study that asks about caretaker satisfaction with law enforcement. Second, the research team analyzed the data reported in this Bulletin at the episode level rather than the child level. Whereas the other Bulletins rely on a unified methodology that counts each child once in the overall and episode-specific estimates, in this Bulletin, researchers counted children who experienced more than one episode brought to the attention of law enforcement more than once. As a result, the estimated number of episodes with police contact-617,900-represents an 
estimated 613,500 individual children, including those who experienced multiple episodes with police contact. Furthermore, as indicated in table 1, this analysis also includes cases in which police were contacted for reasons other than to locate a child thought to be missinga prerequisite for counting youth as reported missing in NISMART-2.

The National Household Survey of Adult Caretakers was conducted during 1999 using computer-assisted telephone interviewing to collect information from a national probability sample of households. Researchers completed 16,111 interviews with an adult primary caretaker, resulting in an 80-percent cooperation rate among eligible households with children and a 61-percent response rate. ${ }^{1}$ Adult caretakers identified 31,787 children in the National Household Survey of Adult Caretakers sample. The researchers weighted the adult interview data to reflect the U.S. Census-based population of children. For additional details about the methodology used for this survey, see OJJDP's NISMART-2 Household Survey Methodology Technical Report (Hammer and Barr, forthcoming).

The research team designed the National Household Survey of Adult Caretakers to screen potentially countable NISMART-2 episodes; to collect demographic information about the household and its members; and to conduct indepth followup interviews about family abductions, nonfamily abductions, runaway/thrownaway episodes, and missing child episodes that involved a child who was lost, injured, or stranded, or who was missing due to a benign explanation (e.g., a miscommunication between a parent and child). Toward the end of each interview, researchers asked a series of questions about police contact, including questions about when and why the caretaker contacted police, how long police took to respond, what police did when they responded, and the caretaker's level of satisfaction with the way in which police handled the case.

\footnotetext{
${ }^{1}$ The American Association for Public Opinion Research (AAPOR) defines a response rate as the number of completed interviews with reporting units divided by the number of eligible reporting units in the sample; AAPOR defines the cooperation rate as the number of cases interviewed divided by the number of eligible units ever contacted (American Association for Public Opinion Research, 2006). The NISMART-2 response rate and cooperation rate were computed with AAPOR formulas RR4 and COOP2, respectively.
}

The overall estimates in tables 1 through 6 are based on episode counts that include nonfamily abduction episodes and missing involuntary, lost, or injured episodes in which children were involuntarily missing because they were lost, injured, or stranded. However, the researchers did not report episode-specific estimates for these two types of episodes because each of these categories did not contain enough sample cases to produce reliable estimates.

The researchers based all estimates on cases with complete data only; they excluded cases with "refused," "don't know," or otherwise missing responses to relevant questionnaire items from the estimates and comparisons. The number of cases lost due to item nonresponse varies from item to item and ranges from 5 percent to 12 percent of all eligible episodes.

\section{Results}

Caretakers might contact police to report a missing child or for some other reason related to a missing child type episode, such as to report a crime or to recover a child whose whereabouts are known. Table 1 shows that 72 percent of the episodes with caretaker-police contact were missing child reports. ${ }^{2}$ Episodes with children missing for benign reasons were the most likely to involve a missing child report, followed by episodes in which the child ran away or was thrown away. Family abduction episodes, however, involved a missing child report in about half of the cases, with the remainder coming to the attention of law enforcement for other reasons.

\section{Type of Police Response}

Table 2 shows that episodes involving caretakers who contacted the police resulted in the dispatch of officers to the household or scene 68 percent of the time. Differences in the percentage of episodes in which officers were dispatched are not statistically significant.

The "Investigative Checklist for First Responders" provides a framework to help law enforcement perform

\footnotetext{
2 Differences in the relative numbers of episodes involving a missing child report are significant at the 95-percent confidence level for each of the types of episodes that appear in table 1.
} 
Table 1: Reason for Police Contact by Type of Episode

\begin{tabular}{lcc} 
& \multicolumn{2}{c}{ Reason for Police Contact } \\
\cline { 2 - 3 } $\begin{array}{l}\text { Type of } \\
\text { Episode }\end{array}$ & $\begin{array}{c}\text { Reported Missing } \\
\text { (weighted row } \\
\text { percentage) }\end{array}$ & $\begin{array}{c}\text { Other Reason } \\
\text { (weighted row } \\
\text { percentage) }\end{array}$ \\
\hline FA* & 46 & 54 \\
RATA* & 74 & 26 \\
MBE* & 87 & 13 \\
Overall & $\mathbf{7 2}$ & $\mathbf{2 8}$ \\
\hline
\end{tabular}

Notes: $F A=$ family abduction, RATA = runaway/thrownaway, MBE = missing benign explanation. Separate estimates are not reported for MILI (missing involuntarily, lost, or injured) and NFA (nonfamily abduction) episodes because the sample sizes were too small to produce reliable estimates. The estimated 617,900 missing child type episodes with police contact represented in this table should not be compared with the child-level estimates presented in other NISMART Bulletins because of the methodological differences discussed on pages 2-3 of this Bulletin. All estimates are rounded to the nearest percentage.

*Percentages are significantly different at $p<.05$. competent, productive, and successful missing and abducted children investigations (Steidel, 2006). In such investigations, first responders are advised to take written reports; interview the individual who made the initial report, individuals who last had contact with the child, other family members, friends, and associates; obtain a photograph of the missing child; and conduct an immediate, thorough search of the missing child's home, even if the child was reported missing from a different location, and extend the search to surrounding areas.

As shown in table 2, police took a written report for 60 percent of the episodes reported to law enforcement, interviewed a household member 59 percent of the time, and obtained a photograph of the child in 26 percent of the cases. ${ }^{3}$ Police gave caretakers a copy of the written report in 36 percent of the episodes in which they prepared a report. Police are significantly more likely to write a report and obtain a photograph of the child

Table 2: Type of Police Response by Type of Episode

Type of Episode

(weighted column percentages)

\begin{tabular}{|c|c|c|c|c|}
\hline Type of Police Response & FA & RATA & MBE & Overall \\
\hline Police dispatched to household & 67 & 62 & 71 & 68 \\
\hline Took telephone report & 44 & 40 & 35 & 38 \\
\hline Took written report* & 43 & 85 & 49 & 60 \\
\hline Gave copy to caretaker $^{\dagger}$ & 56 & 36 & 28 & 36 \\
\hline Obtained photo of child* & 14 & 41 & 23 & 26 \\
\hline Interviewed household member* & 46 & 76 & 55 & 59 \\
\hline Searched, looked around ${ }^{\ddagger}$ & 23 & $N / A$ & $\mathrm{~N} / \mathrm{A}$ & 21 \\
\hline Questioned witnesses/suspects $^{\ddagger}$ & 32 & N/A & $N / A$ & 37 \\
\hline Promised surveillance $^{\ddagger}$ & 24 & N/A & $\mathrm{N} / \mathrm{A}$ & 22 \\
\hline Promised to investigate ${ }^{\S}$ & 42 & $N / A$ & oll & 41 \\
\hline Referred case to other justice agency* & 36 & 18 & 2 & 16 \\
\hline
\end{tabular}

Notes: $\mathrm{FA}=$ family abduction, RATA = runaway/thrownaway, $\mathrm{MBE}=$ missing benign explanation. Base counts for specific episodes vary from the totals for type of police response because of item nonresponse and because of "don't know" and "refused" responses in the data. The loss of episodes because of item nonresponse ranges from 5 percent to 12 percent of cases. The overall estimate includes the MILI (missing involuntarily, lost, or injured) and NFA (nonfamily abduction) episodes that are based on too few sample cases to report separately.

* Differences in row values are statistically significant at $p<.05$.

† Base numbers for these percentages are those cases in which police took a written report.

¥ These questions were asked in the FA and NFA interviews only.

$\S$ This question was asked only in the general interview that covered the MBE and MILI episodes, FA interview, and NFA interview.

\| Estimate is based on too few sample cases to be reliable. 
for runaway/thrownaway episodes compared with other types of episodes. Family abductions are least likely to result in police writing a report or obtaining a photo of the child involved in the episode.

\section{Time of Police Response}

Table 3 presents the caretaker-based estimates for the time it took police to arrive at the household or scene from the time they were contacted. Overall, police arrived at the household or scene in less than 30 minutes after contact for an estimated 70 percent of cases brought to their attention. None of the differences in time to arrival for the various types of episodes are statistically significant.

\section{Satisfaction With Law Enforcement}

Table 4 indicates that caretakers were satisfied with the way in which police handled 61 percent of the episodes brought to their attention. The differences in caretaker satisfaction with police response to the various types of episodes are all statistically significant, and caretakers whose children were missing for benign reasons reported the highest level of satisfaction (75 percent). Caretakers were least satisfied with the way in which police handled family abductions (45 percent).

The National Study of Law Enforcement Policies and Practices Regarding Missing Children and Homeless Youth (Research Triangle Institute, 1993) found that parents of missing children are more satisfied when officers pay an in-person visit, request a photograph of the child, and keep in contact during the investigation (Steidel, 2006). NISMART-2 supports the positive association between parent satisfaction and the dispatch of officers to the home or scene.

Table 5 shows that the majority of caretakers were satisfied with the way in which police handled the case when police officers were dispatched to the household or scene (74 percent), while only 35 percent were satisfied when

\footnotetext{
${ }^{3}$ The difference between the episode-specific estimates for interviewing household members is statistically significant at the 95-percent confidence level, with runaway/thrownaway episodes most likely to elicit interviews of household members.
}

Table 3: Time From Police Contact to Arrival at Household or Scene

Type of Episode

\begin{tabular}{lcccc} 
& \multicolumn{4}{c}{ (weighted column percentages) } \\
\cline { 2 - 5 } Contact to Arrival & FA & RATA & MBE & Overall \\
\hline Less than $\mathbf{3 0}$ minutes & 78 & 54 & 77 & $\mathbf{7 0}$ \\
$\mathbf{3 0}$ minutes or more & 22 & 46 & 23 & $\mathbf{3 0}$ \\
\hline
\end{tabular}

Notes: $\mathrm{FA}=$ family abduction, RATA $=$ runaway/thrownaway, $\mathrm{MBE}=$ miss ing benign explanation. The overall estimate includes the MILI (missing involuntary, lost, or injured) and NFA (nonfamily abduction) episodes that are based on too few sample cases to report separately. All estimates are rounded to the nearest percentage.

Table 4: Caretaker Satisfaction With Police by Type of Episode

Level of Satisfaction (weighted row percentages)

\begin{tabular}{lcc}
\cline { 2 - 3 } Type of Episode & Satisfied & Dissatisfied \\
\hline FA & 45 & 55 \\
RATA & 53 & 47 \\
MBE & 75 & 25 \\
Overall & 61 & 39 \\
\hline
\end{tabular}

Notes: FA = family abduction, RATA = runaway/thrownaway, MBE $=$ missing benign explanation. The overall estimate includes the MILI (missing involuntary, lost, or injured) and NFA (nonfamily abduction) episodes that are based on too few sample cases to report separately. All estimates are rounded to the nearest percentage. Percentages for episode types are significantly different at $p<.05$.

officers were not dispatched. Caretakers were also more likely to be satisfied with the way in which police handled runaway/thrownaway episodes and episodes in which the child was missing due to benign reasons as compared with family abductions.

Table 6 examines the association between caretaker satisfaction and the time it took police to arrive after the initial contact. These estimates suggest that caretakers are significantly more likely to be satisfied with the way in which police handled the case when the response time was less than 30 minutes ( 84 percent); 54 percent of 
Table 5: Caretaker Satisfaction by Police Response

Type of Episode

FA

RATA*

MBE

Overall*
Police Response

Dispatched to household or scene

Not dispatched

Dispatched to household or scene

Not dispatched

Dispatched to household or scene

Not dispatched

Dispatched to household or scene

Not dispatched
Percent Satisfied

48

39

73

22

84

51

74

35

Notes: FA = family abduction, RATA = runaway/thrownaway, MBE = missing benign explanation. The overall estimate includes the MILI (missing involuntary, lost, or injured) and NFA (nonfamily abduction) episodes that are based on too few sample cases to report separately. All estimates are rounded to the nearest percentage.

${ }^{*}$ Differences in percentages are significantly different at $p<.05$.

Table 6: Overall Caretaker Satisfaction by Time of Police Response

Time to Police

Response

Less than 30 minutes

30 minutes or more

Notes: The overall estimate includes the MILI (missing involuntary,

lost, or injured) and NFA (nonfamily abduction) episodes that are based

on too few sample cases to report separately. All estimates are

rounded to the nearest percentage. Differences in percentages are sig-

nificantly different at $p<.05$.

cases had satisfied caretakers when the police took 30 minutes or more to arrive at the scene.

\section{Implications}

Despite recommendations that law enforcement dispatch an officer in response to every report concerning a missing child (Steidel, 2006), estimates based on the NISMART-2

National Household Survey of Adult Caretakers indicate that officers are dispatched to the household or scene in 68 percent of the cases involving reports of a child who is or may be missing.

It is possible that some law enforcement agencies may not be aware of the guidelines contained in Missing and Abducted Children: A Law-Enforcement Guide to Case Investigation and Program Management, which were first published in 1994 (Steidel, 2006). Another possible reason why law enforcement agencies did not dispatch officers in response to every report of a potentially missing, abducted, or runaway/thrownaway child may reflect competing priorities for personnel and other resources. If individual agencies do not have enough officers to handle all incoming reports according to the best practice guidelines, they may be forced to make triage decisions about the children who are most likely to be in immediate danger rather than treating each missing child report as if the child is in immediate danger.

It is also possible that well-informed law enforcement personnel and policymakers do not, in spite of official policies, believe that the recommendation for universal dispatch of police in all missing children related reports is warranted or efficacious. If there are indeed such doubts, then research is needed to assess whether a universal dispatch policy results in better outcomes than a policy in which dispatch is conditioned on certain risk factors. On the other hand, if there is general consensus about the need for universal dispatch in the law enforcement community, then more discussion is needed about how to provide the funding and personnel to achieve this goal.

\section{References}

American Association for Public Opinion Research (AAPOR). 2006. Standard Definitions: Final Dispositions of Case Codes and Outcome Rates for Surveys, 4th ed. Lenexa, KS: AAPOR. 
Hammer, H., and Barr, M.K. (Forthcoming). Second National Incidence Studies of Missing, Abducted, Runaway, and Thrownaway Children (NISMART-2) Household Survey Methodology Technical Report. Washington, DC: U.S. Department of Justice, Office of Justice Programs, Office of Juvenile Justice and Delinquency Prevention.

Research Triangle Institute. 1993. National Study of Law Enforcement Policies and Practices Regarding Missing Children and Homeless Youth. Washington, DC: U.S. Department of Justice, Office of Justice Programs, Office of Juvenile Justice and Delinquency Prevention.

Steidel, S.E. 2006. Missing and Abducted Children: A Law-Enforcement Guide to Case Investigation and Program Management, 4th ed. Alexandria, VA: National Center for Missing \& Exploited Children.

This Bulletin was prepared under grant number 95-MC-CX-K004 from the Office of Juvenile Justice and Delinquency Prevention (OJJDP), U.S. Department of Justice.

Points of view or opinions expressed in this document are those of the authors and do not necessarily represent the official position or policies of OJJDP or the U.S. Department of Justice.

The Office of Juvenile Justice and Delinquency Prevention is a component of the Office of Justice Programs, which also includes the Bureau of Justice Assistance; the Bureau of Justice Statistics; the Community Capacity Development Office; the National Institute of Justice; the Office for Victims of Crime; and the Office of Sex Offender Sentencing, Monitoring, Apprehending, Registering, and Tracking (SMART).
For Further Information

This is the final Bulletin in the NISMART series. The first Bulletin, National Estimates of Missing Children: An Overview, describes the NISMART-2 component studies and estimating methodology, defines the types of episodes studied, and summarizes NISMART-2 estimates of missing children. Four Bulletins in the series report NISMART-2 findings on specific categories of missing children: Children Abducted by Family Members: National Estimates and Characteristics, Nonfamily Abducted Children: National Estimates and Characteristics, Runaway/Thrownaway Children: National Estimates and Characteristics, and National Estimates of Children Missing Involuntarily or for Benign Reasons. Another Bulletin in the series, National Estimates of Missing Children: Selected Trends, 1988-1999, presents results of a special analysis comparing selected findings from NISMART-2 and its predecessor, NISMART-1. The seventh in the series, Sexually Assaulted Children: National Estimates and Characteristics, presents another special topic analysis based on NISMART-2 findings.

NISMART Questions and Answers, a fact sheet, offers a straightforward introduction to NISMART-2. It answers anticipated questions - such as What is NISMART? Have abductions by strangers declined or increased? and Why can't I compare NISMART-1 statistics with NISMART-2 statistics?-to help explain NISMART's purpose, methodology, and findings.

AII NISMART-related publications are available at OJJDP's Web site, www.ojp.usdoj.gov/ojjdp.

\section{Acknowledgments}

Heather Hammer, Ph.D., is a Senior Study Director at the Temple University Institute for Survey Research, Philadelphia, PA, and Principal Investigator of NISMART-2. David Finkelhor, Ph.D., is Professor of Sociology and Director, Crimes against Children Research Center, University of New Hampshire, and Advisor to NISMART-2. Richard K. Ormrod, Ph.D., is Research Professor of Geography at the University of New Hampshire Crimes against Children Research Center. Andrea J. Sedlak, Ph.D., is Associate Director of Human Services Research at Westat, Inc.; Project Director of the NISMART-2 Unified Estimate, Juvenile Facilities Study, and Law Enforcement Study; and Advisor to the NISMART-2 Household Survey. Carol Bruce is a Senior Research Analyst at Westat, Inc. 
U.S. Department of Justice

PRESORTED STANDARD

Office of Justice Programs

Office of Juvenile Justice and Delinquency Prevention

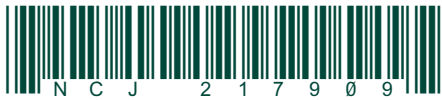

POSTAGE \& FEES PAID

DOJ/OJJDP

PERMIT NO. G-91

Washington, DC 20531

Official Business

Penalty for Private Use $\$ 300$ 